\title{
EMPREITEIROS E \\ IMPRENSA: A ATUAÇÃO \\ DOS EMPRESÁRIOS DA \\ CONSTRUÇÃO PESADA \\ JUNTO AOS VEÍCULOS \\ DE COMUNICAÇÃO \\ ANTES E DURANTE A \\ DITADURA CIVIL-MILITAR \\ BRASILEIRA (1964-1988)
}

Universidade Federal Rural do Rio de Janeiro

Contato

Depto. de História e Relações Internacionais

BR-465 - km 7

23897-000 - Rio de Janeiro - Brasil phpcampos@yahoo.com.br

- Pedro Henrique Pedreira Campos*

Universidade Federal Rural do Rio de Janeiro

Rio de Janeiro - Rio de Janeiro - Brasil

\section{Resumo}

Este artigo analisa a atuação dos empresários brasileiros da construção pesada junto aos organismos de imprensa antes e durante a ditadura civil-militar brasileira. Através do acesso a memórias e fontes primárias do setor, verificamos o elevado interesse desses agentes pelos jornais de grande circulação no país e pelo poder de seus dirigentes, dado o controle que estes dispunham sobre veículos de grande circulação regional e nacional. Notamos uma alteração na atuação dos empresários da construção junto à imprensa antes e durante a ditadura, havendo uma intensificação das ações desses agentes junto a jornais escritos na própria escalada da emergência econômica e política dos empreiteiros após o golpe de 1964.

\section{Palavras-chave}

Empreiteiras - imprensa - ditadura civil-militar brasileira - empresariado Estado.

* Professor do Departamento de História e Relações Internacionais da Universidade Federal Rural do Rio de Janeiro e doutor em História pela Universidade Federal Fluminense. 


\title{
CONTRACTORS
}

AND THE PRESS: THE

PERFORMANCE OF

HEAVY CONSTRUCTION

ENTREPRENEURS ALONG

WITH THE MEDIA

BEFORE AND DURING

THE BRAZILIAN CIVIL-

MILTARY DICTATORSHIP

(1964-1988)

Contact

Universidade Federal Rural do Rio de Janeiro

Depto. de História e Relações Internacionais BR-465 - km 7

23897-000 - Rio de Janeiro - Brazil phpcampos@yahoo.com.br

- Pedro Henrique Pedreira Campos*

Universidade Federal Rural do Rio de Janeiro

Rio de Janeiro - Rio de Janeiro - Brazil

\begin{abstract}
This article analyzes the performance of the Brazilian executives of heavy construction together with the press organizations before and during the Brazilian civil-military dictatorship. Through the access to memories and primary sources of the sector, we verified the high interest of these agents in the newspapers of great circulation in the country and the power of its leaders, given the control these had on vehicles of great regional and national circulation. We noticed a change in the performance of construction entrepreneurs with the press before and during the dictatorship, with an intensification of the actions of these agents along with newspapers written in the very escalation of the economic and political emergence of contractors after the 1964 coup.
\end{abstract}

\section{Keywords}

Contractors - press - Brazilian civil-military dictatorship - business - State. 
A ditadura civil-militar brasileira impactou intensamente a imprensa brasileira nos seus mais de vinte anos. Após um golpe de Estado que foi aclamado e apoiado pela maior parte dos jornais de grande circulação, em especial os do Rio de Janeiro e de São Paulo, a situação ganhou ares mais complexos ao longo do regime. Alguns jornais começaram, já a partir de 1964, a tecer críticas ao governo golpista, enquanto outros apoiaram Castelo Branco e os outros ditadores que o sucederam. Esses organismos de imprensa que se aproximaram do regime e atuaram como autênticos sócios da ditadura, cresceram e foram amplamente beneficiados pelas políticas implementadas naquele período. Já outros foram perseguidos, tiveram seus anunciantes coagidos pela ditadura e alguns deles foram alvos de compra por parte de empresários próximos aos círculos máximos do poder, os empreiteiros de obras públicas. Era uma forma de a ditadura sufocar uma imprensa de oposição e combativa e também um mecanismo para esses empresários disporem de um canal para exercício do seu poder junto ao aparelho de Estado e à sociedade. Conforme veremos neste ensaio, mesmo sendo uma ditadura, a imprensa dispunha de um papel relevante nas disputas políticas e na correlação de força entre classes sociais e frações de classe ao longo do regime. Para tal, iniciaremos a análise em meados da década de 1950, desde o princípio do governo Kubitschek, momento no qual esses empresários emergiram fortemente em seu poder econômico e político, e atravessaremos a década de 1960 e o período da ditadura civil-militar, verificando mudanças e permanências na relação entre empreiteiras, imprensa e Estado em meio a esses diferentes períodos históricos.

Segundo Antônio Gramsci, um jornal pode desempenhar a função de aparelho privado de hegemonia, generalizando um interesse particular e suas concepções de mundo a toda a sociedade, tentando muitas vezes conformar um consenso social em torno de certas ideias, projetos e bandeiras. Através de um projeto pré-determinado, jornais e revistas poderiam atuar como "partidos", "frações de partido" ou "funções de determinado partido". Conforme veremos ao longo desse texto, um partido dos empreiteiros de obras públicas já estava organizado desde o final da década de 1950, o Sindicato Nacional da Construção Pesada - Sinicon. Esse aparelho da sociedade civil dispunha de um projeto claro de poder e usou os organismos de imprensa adquiridos pelos empresários da construção durante a ditadura como me-

1 GRAMSCI, Antônio. Cadernos do cárcere, vol. 2. 4 a edição. Rio de Janeiro: Civilização Brasileira, 2006, p. 197-213. 
canismo para viabilizar certos propósitos políticos de que os empreiteiros dispunham. Assim, conforme tentaremos argumentar, esses agentes usaram jornais de grande circulação adquiridos ao longo do regime como uma ferramenta para exercer uma função do partido dos empreiteiros, qual seja, a de ampliar o seu poder no seio do aparelho de Estado.

As empresas brasileiras de construção pesada² datam em boa medida dos anos 1930, 1940 e 1950, sendo fundadas em meio ao processo de deslocamento do eixo de acumulação de capital do país do campo para a cidade, com o desenvolvimento industrial do período varguista. Essas empresas são contratadas sobretudo por agências do aparelho de Estado para realizar obras de infraestrutura, de modo a dar base a esse novo padrão de acumulação, calcado no setor urbano e industrial. Durante o governo Kubitschek, houve amplas demandas ao setor, fazendo com que as empreiteiras ascendessem em seu poder e riqueza, deixando de ter escala predominantemente local e regional. Assim, elas passaram a se organizar nacionalmente em entidades como a Câmara Brasileira da Indústria da Construção - Cbic, de 1957, e abrangendo empresários da construção pesada e do ramo imobiliário - e o Sinicon, fundado em 1959 no Rio, e que abrangia exclusivamente empreiteiros de obras públicas. Esse órgão era poderoso e articulado politicamente e teve participação de seus principais agentes no golpe civil-militar de $1964{ }^{3}$ Após o golpe, os empreiteiros tiveram franco acesso ao poder durante a ditadura e foram significativamente beneficiados pelas políticas estatais implementadas ao longo do regime. ${ }^{4}$

Além dos periódicos de viés "técnico" e de circulação mais restrita, como a revista $O$ Empreiteiro e outras, os empresários da construção mostraram grande interesse pelos veículos de comunicação de ampla circulação em sua trajetória. Os construtores foram importantes anunciantes e usaram jornais e mídias como meio para atingir certos objetivos, em geral relacionados ao Estado e às políticas públicas. Em maio de 1985, em meio à transição política, o Sinicon, em parceria com a Comissão de Obras Públicas da Cbic,

\footnotetext{
${ }^{2}$ O ramo de engenharia da indústria da construção pesada é o responsável por obras de infraestrutura tocadas pelas empreiteiras, na forma de intervenções nas áreas de transportes, energia, saneamento, habitação e outros. São projetos como rodovias, ferrovias, portos, aeroportos, usinas hidrelétricas e termelétricas, linhas de transmissão etc.

3 Para isso, ver a atuação de empreiteiros como Haroldo Poland e outros em DREIFUSS, René Armand. 1964: a conquista do Estado. $3^{\text {a }}$ edição. Petrópolis: Vozes, 1981 [1981].

4 Sobre a atuação das empreiteiras na ditadura, ver CAMPOS, Pedro Henrique Pedreira. Estranhas catedrais: as empreiteiras brasileiras e a ditadura civil-militar, 1964-1988. Niterói: Eduff, 2014.
} 
decidiu em reunião que atuaria em três frentes para alcançar suas finalidades, sendo a imprensa uma delas, além dos poderes Executivo e Legislativo. ${ }^{5}$ Eram comuns ainda os informes e anúncios em grandes jornais com a defesa de objetivos do setor, como em agosto de 1986, quando o Sinicon publicou nota em jornais do Rio defendendo a volta da vinculação de recursos para investimentos. ${ }^{6}$ Eram também comuns representantes do setor escreverem artigos em jornais, inclusive como articulistas fixos, como Francis Bogossian n'O Globo e Emílio Odebrecht na Folha de S. Paulo no início do século XXI.

A imprensa brasileira, como em outras partes do mundo, tem vínculo histórico com empresas interessadas na difusão de suas ideias, valores e projetos, e no uso do veículo como mecanismo político de pressão junto a agências do aparelho estatal. Nos arquivos diplomáticos norte-americanos, o historiador Carlos Fico verificou o desprezo dos funcionários da embaixada dos Estados Unidos pelos jornais brasileiros. Esses eram vistos como oportunistas, irresponsáveis, indignos de confiança e, corriqueiramente, pagos: "centenas de artigos que se pretendem notícias honestas são, na verdade, comprados ou pagos pelos interesses das companhias, organizações ou políticos".

Exemplo de ação empresarial que deu suporte a um veículo de imprensa, no caso um grande grupo de comunicação, foi a relação das empresas de Assis Chateaubriand, os Diários Associados, com o grupo Light. Nos anos 1920, a companhia canadense aparentemente ajudou Chatô a comprar O Jornal, ponto de partida para criação do seu império da comunicação e que incluía ligações com políticos e empresários. Segundo o relato de Samuel Wainer, os jornais impressos de controle do grupo Diários Associados tinham uma relação de vassalagem em relação à Light. ${ }^{8}$ Isso coincide com outros relatos que apontam como interesses empresariais podiam condicionar ou determinar reportagens, notícias, editoriais ou toda a orientação de um jornal. Da outra parte, havia uma estratégia das empresas de usar a imprensa como meio para atingir determinadas finalidades.

Particularmente os construtores pareciam ser recorrentemente acessados por chefes do Executivo e ministros para divulgar suas obras, conforme se vê no relato do jornalista Jorge Ferreira:

\footnotetext{
Informe Sinicon, ano II, no 5, 31 de maio de 1985.

6 Informe Sinicon, ano III, nº 8, agosto de 1986.

7 FICO, Carlos. O grande irmão: da Operação Brother Sam aos anos de chumbo; o governo dos Estados Unidos e a ditadura militar brasileira. $2^{a}$ edição. Rio de Janeiro: Civilização Brasileira, 2008 [2008], p. 45.

8 WAINER, Samuel. Minha razão de viver: memórias de um repórter. 10ª edição. Rio de Janeiro: Record, 1988 [1987], p. 114-5.
} 
Eu bebia com o Jânio desde que ele era vereador, era amigo dele, até onde o Jânio pode ser amigo de alguém. Aí, veio o Jânio prefeito, o Jânio governador. A gente precisava mostrar que o Jânio sabia gerenciar. Só que custava 20\%. Quem dava o dinheiro eram os empreiteiros. Alguém do governo chegava na Camargo Corrêa e dizia: Arranja aí dez mil-réis para sair uma reportagem em $O$ Cruzeiro.?

O relato indica como a promoção política de alguns administradores parecia passar por matérias pagas por empreiteiras em veículos de comunicação. O mesmo jornalista relata que fez matérias pagas para divulgar obras tocadas pelas administrações estatais de Eliseu Resende, Mário Andreazza, Adhemar de Barros, Juscelino Kubitschek e Israel Pinheiro. ${ }^{10}$

Empresários da construção influíam na imprensa de maneira pontual, em matérias ou editoriais, para pressionar por obras ou pagamento de débitos do governo. Porém, alguns empreiteiros deram um salto nas suas relações com esses veículos, tornando-se proprietários de empresas de comunicação. Foi o caso do empreiteiro Henry Maksoud, dono da empresa de projetos de engenharia paulista Hidroservice, a maior firma do segmento no país. Maksoud era um poderoso empresário do setor da construção civil que tinha um perfil de liderança no setor. Assim, ele chegou a presidir o Instituto de Engenharia de São Paulo (IE), importante organismo da sociedade civil que tinha projeção e poder junto à prefeitura paulistana e ao governo estadual paulista. ${ }^{11}$ Quando presidiu o IE, Maksoud apoiou a campanha "em defesa da engenharia brasileira", lançada pelo Clube de Engenharia do Rio de Janeiro e apoiada por outras organizações empresariais do segmento da construção. Tratava-se de um momento contrário à política desenvolvida pelo governo Castello Branco (1964-1967) de contratar empresas de engenharia estrangeiras em detrimento das nacionais para realização de projetos de obras e intervenções de infraestrutura no país. ${ }^{12}$

\footnotetext{
CARVAlHO, Luiz Maklouf. Cobras criadas: David Nasser e O Cruzeiro. $2^{\text {a }}$ edição. São Paulo: Ed. Senac-SP, 2001, p. 471.

${ }^{10}$ CARVALHO, Luiz Maklouf. Cobras criadas, op. cit., p. 469-70.

${ }^{11}$ INSTITUTO DE ENGENHARIA. Engenharia no Brasil: 90 anos do Instituto de Engenharia, 1916-2006. São Paulo: Instituto de Engenharia, 2007.

${ }^{12}$ Ver mais sobre isso em CLUBE DE ENGENHARIA. Luta pela engenharia brasileira. Rio de Janeiro: Clube de Engenharia, 1967; ROTSTEIN, Jaime. Em defesa da engenharia brasileira. Rio de Janeiro: Clube de Engenharia, 1966; CAMPOS, Pedro Henrique Pedreira. Um projeto de hegemonia em plena ditadura: o Clube de Engenharia e a campanha em defesa da engenharia brasileira (1964-1967). In: CORRÊA, Maria Letícia E PAULA, Dilma Andrade de (org.). Intelectuais e desenvolvimento: perspectivas da pesquisa em história. Rio de Janeiro: Contracapa, 2015, p. 203-231.
} 
Em 1974, Maksoud ampliou seus horizontes de atividades ao comprar o grupo editorial Visão, responsável pela revista Visão, carro-chefe do grupo, além dos periódicos Dirigente Construtor, Dirigente Rural, Dirigente Industrial, Quem é quem, Dirigente Municipal e Perfil, os dois últimos voltados para a administração pública. A editora do grupo lançava livros, como a obra do economista austríaco Friederich Hayek, Os fundamentos da liberdade, editada em parceria com a Editora da Universidade de Brasília (Ed. UnB), com tradução e prefácio do próprio Henry Maksoud, difusor das ideias do autor neoliberal no país. A revista Visão fora fundada em 1952 no Rio, mudando-se em 1957 para São Paulo. Em 1972, foi comprada por Said Farah e, em 1974, por Maksoud, que retirou a tendência independente e mais crítica do periódico, afastando, por exemplo, o redator Zuenir Ventura. A revista estreitou laços com a Associação Brasileira para o Desenvolvimento da Indústria de Base - Abdib - da qual fazia parte a Hidroservice - e comemorou os 20 anos da associação em edição especial. Mário David Andreazza, ministro dos Transportes no período 19671974 e agente próximo a empresários como os empreiteiros de obras públicas, foi capa do periódico. Além disso, anualmente era lançado o guia "Quem é quem na economia brasileira", com dados e listas das maiores empresas do país, setorial e globalmente. ${ }^{13}$ De acordo com informação do periódico $O$ Empreiteiro, O Dirigente Construtor era a segunda revista de maior circulação no setor de construção no país, perdendo apenas para o próprio $O$ Empreiteiro. ${ }^{14}$

Além dos semanários, os empresários da construção tiveram atuação junto à imprensa diária, influindo na linha editorial de importantes jornais de circulação nacional. Isso não se limitou ao período da ditadura, tendo tomado impulso no período das obras do governo Kubitschek, conforme relato de Samuel Wainer:

Em outra ocasião, quando eu estava novamente às voltas com dívidas junto ao Banco do Brasil, um alto funcionário da instituição passou-me uma informação preciosa: havia um empresário estreitamente ligado ao presidente, empreiteiro de obras públicas, que costumava socorrer amigos comuns em apuros. Seu nome: Marcos Paulo Rebello [sic- o correto é Rabello], dono de uma empresa que se responsabilizara por boa parte da construção de Brasília. ${ }^{15}$

\footnotetext{
${ }^{15}$ CEZAR JÚNIOR, Gervásio. Revista Visão e Abdib: entre abalos e diferenças, as críticas ao II PND e a sustentação do projeto burguês. In: SILVA, Carla Luciana E RAUTEMBERG, Édina (org.). História e imprensa: estudos de hegemonia. Porto Alegre: FCM, 2014, p. 243-286. A revista deixou de circular em 1993.

${ }^{14}$ Revista O Empreiteiro, n ${ }^{\circ} 117$, outubro de 1977.

${ }^{15}$ WAINER, Samuel. Minha razão de viver, op. cit., p. 223.
} 
Wainer se refere ao dono da Rabello, principal empreiteira nas obras da nova capital e próximo do presidente da República. A Rabello foi uma construtora mineira que tinha realizado empreendimentos públicos para as gestões de Kubitschek quando este esteve à frente da prefeitura de Belo Horizonte e do governo estadual em Minas Gerais. Na segunda metade da década de 1950, a Rabello era uma das maiores empresas do setor no país. ${ }^{16}$ Wainer indica como teria livrado seu jornal das dívidas:

\begin{abstract}
Fui ao encontro de Rabello, que a princípio tentou negar qualquer ligação com Juscelino. Ao constatar a inutilidade da negativa, tornou-se bastante receptivo e sugeriu que eu lhe vendesse 45\% das ações da Érica, minha empresa. As ações foram efetivamente transferidas para seu nome, e retribuí com material publicitário a ajuda que a Rabello me prestou. De qualquer forma, naquele momento eu conheci uma figura indispensável à decifração dos segredos do poder no Brasil: o empreiteiro. Marco Paulo Rabello era apenas um deles. Muitos outros haveriam de surgir no meu caminho. ${ }^{17}$
\end{abstract}

Esse parece ser o primeiro caso de empresa de construção pesada que se tornou acionista de um veículo de comunicação. Ao deter parte da firma controladora do jornal de Wainer, Rabello tinha acesso a um dos jornais mais importantes do país, com ligação com o grupo político dirigente de então. O Última Hora havia sido fundado em 1951 a pedido direto do presidente Getúlio Vargas, de modo a contrabalançar a imprensa de oposição ao seu governo e logo o jornal estabeleceu laços com empresários que tinham negócios com o governo. ${ }^{18}$

Na sua autobiografia, o diretor do jornal expõe as ações dos empreiteiros junto à imprensa a partir do período JK:

Ainda nos anos 50, a imprensa brasileira tinha como anunciantes, basicamente, pequenos comerciantes - a indústria nacional não alcançara sua maioridade, e tampouco havia grupos financeiros de grande porte (...) Na Primeira República, muitos donos de jornais prosperaram como agentes dos interesses dos exportadores de café. Nos anos 50, os barões do café foram substituídos pelos grandes empreiteiros. Especialmente nos anos JK, quando começou a era das obras portentosas, os empresários do ramo compreenderam que valia a pena contar com jornais amigos; com a cumplicidade

\footnotetext{
${ }^{16}$ FERRAZ FILHO, Galeno Tinoco. A transnacionalização da grande engenharia brasileira. Dissertação de mestrado em Economia, Unicamp, Campinas, 1981.

${ }^{17}$ WAINER, Samuel. Minha razão de viver, op. cit., p. 223.

${ }^{18}$ FERREIRA, Marieta de Moraes \& MESQUITA, Claudia. Os anos JK no acervo da Biblioteca Nacional. In: BIBLIOTECA NACIONAL. Brasiliana da Biblioteca Nacional: guia de fontes sobre o Brasil. Rio de Janeiro: Fundação Biblioteca Nacional / Nova Fronteira, 2001, p. 329-368.
} 
da imprensa, seria sempre mais fácil conseguir obras sem o ritual das concorrências públicas. Seria mais fácil também receber do governo - um mau pagador crônico - o dinheiro a que tinham direito pelas obras executadas. Feitas tais constatações, logo se forjaram sociedades semiclandestinas bastante rentáveis.

Assis Chateaubriand, por exemplo, costumava procurar pessoalmente ministros de Estado, ou mesmo o presidente da República, para solicitar que um trecho de uma determinada obra - uma rodovia, uma hidrelétrica - fosse entregue a esta ou àquela construtora. Ficava claro que, se o pleito não fosse atendido, a ira do jornal desabaria sobre o autor da recusa. Era melhor, portanto, atender ao pedido. Feito o acerto, as empreiteiras premiadas presenteavam o emissário com 10\% do total da quantia orçada para a obra. Geralmente essa porcentagem significava cifras milionárias. (...)

Ministros mais prestativos, dispostos a liberar com agilidade as verbas devidas, mereciam rasgados elogios em editoriais e reportagens. Já os que protelavam pagamentos caíam em desgraça e recebiam ataques duríssimos. De quebra, os meios de comunicação faziam vista grossa para a irresponsabilidade das empreiteiras, que utilizavam material de segunda ordem, fraudavam cálculos e montavam orçamentos fictícios.

Esse tráfico de influência tornou-se particularmente intenso no governo JK, durante o qual se consolidaram fortunas imensas. Um dos principais beneficiários desse período foi precisamente Marco Paulo Rabello, de quem frequentemente se dizia, sem provas concretas, que era sócio de JK. O presidente entregou a tarefa de construir Brasília a Rabello, que só pôde distribuir entre outras empresas as obras de cuja execução não poderia encarregar-se - era muita coisa para um único empreiteiro. Só a construção de Brasília já bastaria para assegurar a alegria de dezenas de homens do ramo, mas houve mais. A rodovia Belém-Brasília, por exemplo. Além do mais, vários governos estaduais se encarregaram de inchar os cofres das empreiteiras às quais denotavam franca e suspeita simpatia com projetos de âmbito regional, mas [sic] também milionários.

A presença dos empreiteiros na cena política brasileira é ainda fortíssima lesse depoimento foi gravado em 1980]. Eles seguem interferindo na nomeação de ministros que agirão nas áreas incluídas em seu universo de interesses, financiando partidos e candidatos, elegendo deputados e senadores, influenciando a linha editorial de jornais e revistas. Negócios desse tipo não costumam deixar rastros, mas é fácil deduzir que nestes últimos anos foram captados dessa forma alguns bilhões, repartidos entre empreiteiros e seus sócios na imprensa. ${ }^{19}$

\footnotetext{
${ }^{19}$ WAINER, Samuel. Minha razão de viver, op. cit., p. 224-5.
} 
O longo relato traz um testemunho sobre a relação entre empreiteiros de obras públicas e jornais de grande circulação. Como se pode perceber, a imprensa parece ter sido usada como meio para atingir as agências estatais, os empreiteiros tentando se utilizar do poder que esses veículos de comunicação detinham para pressionar por ações que lhes convinham. Outras fontes indicam o uso da imprensa na mediação das relações de poder envolvendo empreiteiros de obras públicas e agentes do aparelho de Estado. ${ }^{20}$

O livro de Wainer foi o resultado de entrevista feita por jornalistas com o antigo dono do Última Hora. Para a elaboração do livro, foi feita uma seleção, que acabou suprimindo certas passagens. A pesquisadora Joëlle Rouchou teve acesso às fitas originais e à sua transcrição, trazendo em sua dissertação de mestrado uma passagem do relato de Wainer que ilustra essa mediação feita pelos proprietários de grandes jornais entre empreiteiros e agentes do apareIho de Estado. O trecho parece complementar a passagem anterior, indicando o destino dos recursos despendidos pelas construtoras com a imprensa:

Normalmente os donos de jornais põem nos bolsos. Então o dono do jornal ia ao ministro e dizia assim: "Quero esse trecho para fulano".

O ministro dizia: "Não posso, já me comprometi com beltrano".

"Bom, se você não me der, leva pau".21

O relato sugere que a relação estabelecida entre empreiteiros e altos funcionários do aparato estatal - ministros e autoridades como diretores de estatais e autarquias contratantes de obras públicas - era mediada pelos empresários do setor da comunicação e se dava através de promessas de ameaças ou possibilidades de elogio e promoção pessoal. Esse uso da imprensa de maneira pontual e instrumental pelos empresários do setor acabou evoluindo para formas mais sofisticadas de atuação, como o próprio controle de jornais, conforme ocorreu sob a ditadura.

Antes disso, o jornal de Wainer estabeleceu relações sólidas com os empreiteiros. Com trajetória mais ligada ao PTB que ao PSD, Wainer, que já

\footnotetext{
${ }^{20}$ ANDRADE, Jefferson Ribeiro de. Um jornal assassino: a última batalha do Correio da Manhã. Rio de Janeiro: José Olympio, 1991; GASPARI, Elio. A ditadura escancarada. São Paulo: Companhia das Letras, 2002; CARVALHO, Luiz Maklouf. Cobras criadas, op. cit.; RAUTENBERG, Édina. A revista Veja e as empresas de construção civil durante a ditadura civil-militar. In: SILVA, Carla Luciana \& RAUTEMBERG, Édina (org.). História e imprensa: estudos de hegemonia. Porto Alegre: FCM, 2014, p. 165-206; CAMPOS, Pedro Henrique Pedreira. Estranhas catedrais, op. cit.

${ }^{21}$ Fita $^{\circ} 19$, p. 4/451 do material bruto de Samuel Wainer apud ROUCHOU, Joëlle. Samuel: duas vozes de Wainer. $3^{\text {a }}$ edição. Rio de Janeiro: Ed. UniverCidade, 2004, p. 91.
} 
detinha poder político relevante na gestão JK, teve posição ainda mais central no governo Jango, o que lhe possibilitou uma posição de mediador entre governo e alguns empresários:

Entre 6 de janeiro de 1962 [sic- o correto é 1963], quando Jango assumiu efetivamente o poder, e 31 de março de 1964, a Última Hora não só dispôs de força política como, também, esteve em ótima situação econômica. É que nesse período, mais do que nunca, tive acesso aos empreiteiros deste país e às verbas imensas por eles controladas. Como já disse nessas memórias, não é possível escrever a história da imprensa brasileira sem dedicar um vasto capítulo aos empreiteiros. Não se trata, insisto, de uma exclusividade nacional - desde os tempos do Império romano os responsáveis pela execução de obras públicas mantêm relações especiais com os donos do poder. No governo Goulart, de todo modo, aproximei-me desses homens mais que em qualquer outra época. Isso me permitiu conhecê-los melhor e, também, assegurar à minha empresa dois anos de prosperidade. Alguns meses depois de assumir o cargo, Jango convocou-me para dizer que não tinha confiança no homem que encarregara de fazer a ligação entre o PTB, principal partido do esquema de sustentação do governo, e os empreiteiros que financiavam o partido. Pediu-me que cuidasse do assunto, aceitei a missão. O esquema era simples. Quando se anunciava alguma obra pública, o que valia não era a concorrência - todas as concorrências vinham com cartas marcadas, funcionavam como mera fachada. Valiam, isto sim, os entendimentos prévios entre o governo e os empreiteiros, dos quais saía o nome da empresa que deveria ser contemplada na concorrência. Feito o acerto, os próprios empreiteiros forjavam a proposta que deveria ser apresentada pelo escolhido. Era sempre uma boa proposta. Os demais apresentavam propostas cujas cifras estavam muito acima do desejável, e tudo chegava a bom termo. Naturalmente, as empresas beneficiadas retribuíam com generosas doações, sempre clandestinas, à boa vontade do governo. Nunca participei desses entendimentos preliminares. Minha tarefa consistia em, tão logo se encerrasse a concorrência, recolher junto ao empreiteiro premiado a contribuição de praxe. Não aceitávamos cheques, o pagamento vinha em dinheiro vivo. Uma vez por mês, ou a cada dois meses, eu visitava os empreiteiros e recolhia suas doações, juntando montes de cédulas que encaminhava às mãos de João Goulart. ${ }^{22}$

Esse esquema de propinas, mencionado por Wainer, relacionava empreiteiros ao governo Goulart, tendo mediação do próprio jornalista, conforme o seu relato. O testemunho do acerto de lances de concorrências e pagamento de comissões indica a organicidade dos empreiteiros, que pareciam usar suas entidades e inserção em agências estatais para tal. Os empresários do setor geralmente avaliam o período do início de 1963 a março de 1964 como

${ }^{22}$ WAINER, Samuel. Minha razão de viver, op. cit., p. 237-8. 
positivo no mercado de obras, em uma continuação dos projetos do período JK, após período de certo congelamento das encomendas, nos anos de 1961 e 1962. ${ }^{23}$ Os esquemas irregulares de então serviram como justificativa aos grupos golpistas para a ação armada de abril de 1964 e intervenção imediata em órgãos como o Departamento Nacional de Estradas de Rodagem - DNER. ${ }^{24}$

Com o golpe de 1964, alguns empresários e jornais relacionados ao governo Jango foram perseguidos. Marco Paulo Rabello passou a perder concorrências seguidamente ${ }^{25}$ e o jornal de Wainer teve sua sede no Rio depredada e a sucursal em Recife fechada, sendo seu chefe local torturado pelas tropas do IV Exército. O dono do jornal, cassado pelo primeiro Ato Institucional, pressentindo que seria alvo dos golpistas, refugiou-se na embaixada do Chile. Dois dias depois de chegar ao local, Wainer relata ter recebido uma visita:

No dia 3 de abril de 1964, o próprio embaixador do Chile comunicou-me que uma visita estava à minha espera em outra sala. Era Ibrahim Sued. Fiquei intrigado: segundo as leis de asilo, eu só poderia receber familiares na embaixada. O diplomata chileno esclareceu que abrira uma exceção porque Ibrahim Sued era um homem muito importante. Fui ao encontro do ilustre visitante, e Ibrahim explicou-me que estava ali em nome de um grupo de empreiteiros interessados em comprar a Última Hora. Eram os empreiteiros que mais tarde se ligariam estreitamente ao coronel Mário Andreazza.

- Não quero vender a Última Hora, Ibrahim - informei.

- Você é maluco?, espantou-se ele. - Não vê que não tem condições de manter o jornal? Repeti que não tinha intenção alguma de desfazer-me da Última Hora.

- Eles pagam o preço que você estabelecer - ressalvou Ibrahim.

Insisti na negativa, e a conversa começou a morrer. Alguns anos depois, ao cabo de penosas negociações que serão aqui relatadas, a Última Hora acabou sendo comprada pelo mesmo grupo de empreiteiros que haviam incumbido Ibrahim Sued de ir ao meu encontro. Naquele instante, porém, eu achava conveniente conservar o jornal até que a situação brasileira se tornasse menos sombria. Eu ainda não compreendera que o regime militar teria vida longa. Não alcançara, também, até que ponto os empreiteiros estavam dispostos a ampliar sua influência direta sobre nossa imprensa.

Alguns meses depois, exilado em Paris, recebi a visita de um emissário desse grupo de empreiteiros, liderados pelos irmãos Alencar - Maurício, Marcelo e Mário. Os Alencar

\footnotetext{
${ }^{25}$ Ver, por exemplo, QUINTELLA, Wilson. Memórias do Brasil grande: a história das maiores obras do país e dos homens que as fizeram. São Paulo: Saraiva / Vigília, 2008, p. 242-3.

${ }^{24}$ Ver CAMPOS, Pedro Henrique Pedreira. Estranhas catedrais, op. cit., p. 310-311.

${ }^{25}$ FERRAZ FILHO, Galeno Tinoco. A transnacionalização da grande engenharia brasileira, op. cit.
} 
haviam cultivado lucrativas ligações com multinacionais e militares, e pressentiam que, com o golpe de 64 , sua hora chegara. ${ }^{26}$

Segundo o relato de Wainer, apenas dois dias após o golpe, um grupo de empreiteiros propôs comprar o Última Hora, com o objetivo de ampliar seu poder e influência política. Os líderes do grupo eram os donos da Metropolitana, provavelmente incentivados por figuras responsáveis pelo golpe e pelo novo governo. O então presidente da Metropolitana, Haroldo Poland, era próximo do coronel Golbery do Couto e Silva e atuava com ele no Ipes. ${ }^{27}$ A ligação posterior desses empreiteiros com Andreazza é também assinalada por Wainer.

A passagem aponta ainda os novos intermediários dos empreiteiros com a imprensa e o aparelho de Estado após o golpe. Ibrahim Sued, o mensageiro desses empresários, era um dos jornalistas que passou a fazer essa intermediação. Outro foi David Nasser, que trabalhou para Assis Chateaubriand nos Diários Associados e, segundo Wainer, foi um dos escolhidos para herdar o conglomerado. Em uma ditadura com poderoso posicionamento político dos empreiteiros, Nasser tentou se utilizar das possibilidades abertas pela nova conjuntura:

Ao ampliar sua influência nos Diários Associados, David passou a usar as armas de pressão, da corrupção, eventualmente da chantagem, para fazer fortuna. A partir de 1964, tornou-se o principal intermediário entre os empreiteiros e o governo. Empreiteiros com alguma soma a receber procuravam David Nasser para que ele apressasse o pagamento. Naturalmente, era um trabalho que lhe rendia enormes comissões. ${ }^{28}$

O relato de Wainer em relação a Nasser indica a importância que o jornalista ligado a Chatô teve na relação com os empresários de obras públicas. Nasser era procurado por empreiteiros para tentar facilitar pagamentos e vitórias em concorrências, tendo sido procurado por Marco Paulo Rabello, Murillo Mendes (da Mendes Júnior) e outros. O jornalista montou com o advogado Frederico Gomes da Silva uma empresa de "lobby e serviço de relações públicas". ${ }^{29}$

Boa parte da grande imprensa escrita brasileira fez oposição ao governo Goulart, referindo-se a um suposto perigo comunista e caos administrativo no período. A política cambial do governo Jango prejudicava economicamente as empresas do setor, ao encarecer a importação do papel de jornal,

\footnotetext{
${ }^{26}$ WAINER, Samuel. Minha razão de viver, op. cit., p. 262-3.

${ }^{27}$ GASPARI, Elio. A ditadura derrotada. São Paulo: Companhia das Letras, 2003, p. 167-79; DREIFUSS, René Armand. 1964, op. cit.

${ }^{28}$ WAINER, Samuel. Minha razão de viver, op. cit., p. 185.

${ }^{29}$ CARVALHO, Luiz Maklouf. Cobras criadas, op. cit., p. 383-486.
} 
comprado amplamente no exterior naquele período. O Estado de $S$. Paulo e $O$ Globo defendiam posições da UDN, enquanto o Última Hora se alinhava mais ao PTB. Às vésperas do golpe, jornais alertaram para um suposto risco de "cubanização" do Brasil e o Jornal do Brasil pediu em editorial a intervenção armada. Como assinala Alzira Abreu, nos meses anteriores ao golpe, poucos foram os jornais que não pediram a intervenção militar. ${ }^{30}$

O golpe de 1964 teve amplo apoio da grande imprensa do país, com a exceção praticamente isolada do Última Hora. Jornais que depois passaram a uma postura crítica ao regime, como o Correio da Manhã, defenderam a quebra da ordem institucional. Com o prolongamento do regime, o quadro se modificou e alguns órgãos de imprensa passaram a - ou tentaram - uma atitude crítica ao governo. Houve censura ao longo da ditadura, mas esta foi mais vigorosa entre 1968 e 1978, como indica Maria Aparecida Aquino. A autora chama a atenção para as diversas formas de censura que foram procedidas no período, como a avisada e a prévia, que se abateu sobre a revista Veja e o jornal $O$ Estado de $S$. Paulo. ${ }^{31}$ Porém, quem mais sofreu com a censura foi a pequena imprensa alternativa e de opinião, que foi amordaçada e cerceada. Alguns dirigentes de jornais foram perseguidos, como foi o caso de Hélio Fernandes, que comprou a Tribuna da Imprensa de Lacerda e teve o jornal atacado nos anos $1970 .^{32}$

Já outros veículos jornalísticos ampliaram seus poderes a partir de subordinação e apoio à ditadura. Grupos de comunicação cariocas como $O$ Globo, da família Marinho, O Dia, de Chagas Freitas, e o Jornal do Brasil, de Nascimento Brito, ganharam força com o regime, ampliando sua circulação e desenvolvendo atividades além da imprensa escrita, o que potencializou sua capacidade de ação e poder político. Incêndios múltiplos e quase simultâneos ocorreram em 1969 em quatro emissoras de televisão e foram atribuídos a grupos da esquerda "terrorista". No caso, nenhum grupo da luta armada assumiu as ações, mas os "atentados" renderam às empresas de comunicação recursos de seguros que serviram para renovação e modernização de seus equipamentos. ${ }^{33}$ Além disso, jornais e revistas como Veja e Manchete faziam

\footnotetext{
${ }^{30}$ ABREU, Alzira Alves de. A imprensa e a queda do governo de João Goulart. In: BRAGANÇA, Aníbal \& MOREIRA, Sonia Virgínia (org.). Comunicação, acontecimento e memória. São Paulo: Intercom, 2005, p. 13-21.

${ }^{31}$ AQUINO, Maria Aparecida. Censura, imprensa, estado autoritário (1968-1978), op. cit.

32 GASPARI, Elio. A ditadura escancarada, op. cit., p. 207-21.

${ }^{33}$ Idem, p. 59-67.
} 
edições especiais sobre grandes projetos de engenharia da ditadura, como Transamazônica e Itaipu, em tom de exaltação e apoio. ${ }^{34}$

Um caso notável - talvez o maior de todos - é o da rede de mídia sob controle da família Marinho. O grupo remonta ao jornal $O$ Globo, fundado no Rio de Janeiro em 1925 por Irineu Marinho. Tratava-se de um jornal conservador que apoiou a Revolução de 1930, condenou a Intentona Comunista de 1935, aplaudiu a cassação do PCB em 1947, foi contra a criação da Petrobrás em 1953 e tinha laços com a UDN e com Carlos Lacerda. Após a criação da Rádio Globo, em 1944, o grupo Marinho deu o seu passo mais ousado no período Castello Branco, com a criação da Rede Globo de Televisão, em 1965. Após ter apoiado firmemente o golpe de 1964, a família Marinho fez sociedade com o grupo norte-americano Time Life para a criação da sua rede de TV no Brasil. A associação era ilegal, já que previa a participação de capital estrangeiro em uma rede de televisão no Brasil, algo proibido na Constituição. Mesmo sendo alvo de CPI, o grupo Globo foi apoiado pela ditadura, que defendeu a operação e proporcionou a possibilidade de difusão nacional do sinal da Rede Globo com suporte da política oficial de comunicações do regime. ${ }^{35} \mathrm{O}$ jornalismo da Rede Globo era amplamente favorável à ditadura e é famosa a frase do ditador Médici a respeito do Jornal Nacional, criado em 1969:

Sinto-me feliz, todas as noites, quando ligo a televisão para assistir ao jornal [Nacional]. Enquanto as notícias dão conta de greves, agitações, atentados e conflitos em várias partes do mundo, o Brasil marcha em paz, rumo ao desenvolvimento. É como se eu tomasse um tranquilizante após um dia de trabalho. ${ }^{36}$

Ao final da ditadura, a Rede Globo e as organizações no ramo das comunicações e em outros setores econômicos sob controle da família Marinho tomaram um vulto colossal. O controlador do grupo, Roberto Marinho, tornou-se uma das figuras políticas mais poderosas em meio ao processo de transição política e no novo regime inaugurado com a Constituição de 1988.

\footnotetext{
${ }^{34}$ RAUTENBERG, Édina. A revista Veja e as empresas de construção civil durante a ditadura civil-militar, op. cit., p. 165-206; GASPARI, Elio. A ditadura derrotada, op. cit., p. 197-213.

35 ARÊAS, João Braga. Os Marinho: o monopólio brasileiro do setor de comunicação. In: CAMPOS, Pedro Henrique Pedreira E BRANDÃO, Rafael Vaz da Motta (org.). Os donos do capital: $a$ trajetória das principais famílias empresariais do capitalismo brasileiro. Rio de Janeiro: Autografia, 2017, p. 196-226. Ver também ARÊAS, João Braga. As batalhas de O Globo: ditadura militar, Lula x Collor, privatizações e a vitória do PT em 2002. Curitiba: Prismas, 2015.

${ }^{36}$ Apud ARÊAS, João Braga. Os Marinho: o monopólio brasileiro do setor de comunicação, op. cit, p. 210.
} 
Outros grupos jornalísticos foram amplamente favorecidos pelo regime e atuaram em estreita parceria com o Estado autoritário. Um caso emblemático disso é o grupo Folha, sob controle da família Frias, que atuou de diversas formas em franco apoio ao regime como, por exemplo, colaborando com a Operação Bandeirantes. A Oban era a ação de repressão aos integrantes da resistência armada à ditadura no estado de São Paulo. A iniciativa foi conduzida a partir de uma comissão geral de inquéritos policiais-militares (IPM), proposta durante o governo Costa e Silva pelo ministro da Guerra, general Jayme Portella. A operação foi criada para centralizar o sistema de segurança, subordinado ao presidente da República, em julho de 1969. Seu orçamento, no entanto, era bancado por contribuições privadas e Luiz Macedo Quental, ligado a empreiteiras e à Light, pedia contribuições dos empresários paulistas. Na Fiesp, o ministro Antônio Delfim Netto fez o mesmo e conseguiu contribuições de empresas nacionais como Camargo Corrêa, Folha de S. Paulo, o grupo Ultra e, principalmente, firmas internacionais como Nestlé, General Eletric, Mercedes-Benz, Siemens e outros. A Oban usava métodos como a prisão, tortura e o assassinato dos integrantes da esquerda armada brasileira. ${ }^{37}$

Porém, ao longo da ditadura, nem todos os jornais serviam de suporte ao regime, sendo um exemplo o jornal carioca de Niomar Moniz Bittencourt:

Ao nível da imprensa, o centro da oposição estava localizado no Correio da Manhã, de onde surgiram os excelentes artigos condenando o governo. Antônio Callado, Oto Maria Carpeaux, Carlos Heitor Cony, Marcio Moreira Alves e Hermano Alves eram alguns dos autores da crítica à ditadura. Os jornais chegavam às bancas e praticamente se esgotavam. Se a venda avulsa desse lucro, o Correio da Manhã daquela época teria prosperado rapidamente. A política de Castelo, que acabou culminando com a edição do AI-2, após a vitória da oposição em Minas e Rio, era dissecada impiedosamente. (...) O Correio da Manhã foi asfixiado pelo corte de propaganda. Só com a venda avulsa não dava para aguentar. ${ }^{38}$

O relato do jornalista Fernando Gabeira indica como o governo pressionava empresários para não financiar um organismo de imprensa que não era bem visto pelo governo.

\footnotetext{
37 BANDEIRA, Luiz Alberto Moniz. Cartéis e desnacionalização: a experiência brasileira, 1964-1974. Rio de Janeiro: Civilização Brasileira, 1975; GASPARI, Elio. A Operação Bandeirante, Oban. In: A ditadura escancarada, op. cit., p. 59-67; MELO, Jorge José. Boilesen, um empresário da ditadura: a questão do apoio do empresariado paulista à Oban/Operação Bandeirantes, 1969-1971. Dissertação de mestrado em História, UFF, Niterói, 2012.

${ }^{38}$ GABEIRA, Fernando. O que é isso, companheiro? 26a edição. Rio de Janeiro: Codecri, 1981, p. 30.
} 
O jornal fundado em 1909 por Edmundo Bittencourt era um dos mais tradicionais da imprensa do Rio e, com a morte de seu fundador, sua administração passou para a viúva Niomar Bittencourt. Esta foi duramente pressionada pela repressão estatal para ceder em seu ímpeto opositor nos primeiros anos da ditadura. Após ficar encurralada, inclusive com a prisão do editor após o $\mathrm{AI}-5,{ }^{39}$ Bittencourt aceitou proposta de arrendamento do jornal para um grupo de empreiteiros. Segundo Wainer, o projeto dos empresários era o seguinte:

O grupo de empreiteiros que arrendara o Correio da Manhã, liderado por Maurício Alencar, estava agora interessado em comprar o Última Hora, uma ideia que lhe permitiria consumar um plano diabólico. A ideia desses empreiteiros era esvaziar progressivamente o Correio da Manhã, cuja tiragem caía dia a dia, transferindo para outro jornal, no caso a Última Hora, todos os contratos que parecessem lucrativos..$^{40}$

O Correio da Manhã passou a ser controlado em 1969 por Maurício Alencar e Frederico Gomes da Silva, que lideravam o grupo de empreiteiros interessados no jornal. Niomar Bittencourt preferiu entregar o periódico para esses empresários a fazê-lo para a família Frias, da Folha de S. Paulo, que também fez proposta. Segundo Jefferson Andrade, a intenção dos dois empreiteiros ao arrendar o jornal era criar um veículo para defender a candidatura do ministro dos Transportes Mário David Andreazza à presidência na sucessão de Costa e Silva. O derrame do ditador Costa e Silva frustrou o plano dos empresários, fazendo com que eles forçassem sua decadência. ${ }^{41}$

Antes disso, porém, já a partir de setembro de 1969, as modificações foram visíveis no diário. Até então, o jornal fazia reportagens sobre os prisioneiros liberados com o sequestro do embaixador norte-americano, inclusive com entrevistas, além de notícias sobre a perseguição a Niomar Sodré, com notas duras sobre as medidas autoritárias do regime. Após a aquisição pelos empreiteiros, o jornal passou a órgão de comunicação que mais se assemelhava a um canal oficial de divulgação do governo e dos interesses empresariais dos construtores de obras públicas. No dia da saída de Bittencourt, 11 de setembro, veio propaganda do Clube de Engenharia no jornal ${ }^{42}$ e, dois dias depois, notícia sobre a construção do elevado Paulo de Frontin e

\footnotetext{
39 STEPAN, Alfred. Os militares na política: as mudanças de padrões na vida brasileira. Rio de Janeiro: Artenova, 1975 [1971], p. 157-65.

${ }^{40}$ WAINER, Samuel. Minha razão de viver, op. cit., p. 279.

${ }^{41}$ ANDRADE, Jefferson Ribeiro de. Um jornal assassino, op. cit., p. 231-2.

${ }^{42}$ O Correio da Manhã, 11 de setembro de 1969.
} 
Pedro Henrique Pedreira Campos

Empreiteiros e imprensa: a atuaç̃õo dos empresários da construção pesada junto cos veículos de comunicacãao antes e durante a ditadura civil-militar brasileira (1964-1988)

sobre as ações do ministro dos Transportes, com a reportagem "Andreazza vê crime de lesa-pátria na ação antigoverno".43 Os novos controladores pareciam sinalizar as mudanças no corte editorial do periódico e os empreiteiros se beneficiaram de um veículo com ampla circulação, cadernos populares, como Esportes, e colunistas do porte de Carlos Drummond de Andrade. Já na edição de 14 de setembro, os nomes dos novos donos apareceram na capa do jornal e a nota "Definição" explicava sua reorientação:

Acentua-se, no mundo de hoje, a responsabilidade social dos empresários. Eles não têm somente responsabilidades econômicas e legais, limitadas ao âmbito restrito das empresas que gerem ou administram. Têm, também, responsabilidades para com a sociedade, devendo ter interesse no bem-estar da comunidade, do mundo social que está à sua volta. Cônscios dessas obrigações, resolvemos assumir a direção do CORREIO DA MANHÃ, levados pela convicção de que seu parque industrial está integrado na economia do estado da Guanabara, e seu perecimento, acarretando o desemprego dos seus operários, levaria ao desamparo de cerca de 600 famílias. Acreditamos que, através de métodos e técnicas de administração racional, será possível ter pleno rendimento de seu equipamento, que vinha trabalhando em condições de baixa produtividade e com grande capacidade ociosa. (...)

Compreendemos o papel desempenhado pelas Forças Armadas na vida brasileira. Temos fé em suas convicções democráticas. Conhecemos e admiramos a valiosa cooperação de seus quadros técnicos no desenvolvimento nacional.

Temos certeza que chamadas a intervir no processo político em horas de crise, elas não o fazem animadas de outro propósito senão o de assegurar a garantia da ordem interna, absolutamente necessária ao desenvolvimento global da Nação e ao exercício da vivência democrática.

Como tal comportamento se coaduna com os nossos princípios aqui já enunciados, desnecessário será afirmar o nosso propósito de colaboração com as Forças Armadas, visando a melhor solução para a crise brasileira, a restauração da normalidade democrática e a plena garantia da paz e ordem internas. ${ }^{44}$

Vê-se no trecho como os empreiteiros usaram a justificativa da responsabilidade social para tomar a direção do jornal, escondendo o interesse de difundir suas concepções de mundo e defender a candidatura de Andreazza à presidência. Mostraram ainda estar afinados com o projeto da ditadura e o discurso oficial do papel dos militares na sua intervenção política de então.

\footnotetext{
43 O Correio da Manhã, 13 de setembro de 1969.

${ }^{44}$ O Correio da Manhã, 14 de setembro de 1969.
} 
A partir daquele momento, seriam comuns reportagens sobre as obras do metrô, da usina de ilha Solteira e da nova catedral do Rio, além de informes sobre as atividades da Associação de Diplomados na Escola Superior de Guerra - Adesg e da Sociedade dos Engenheiros da Guanabara. A sua tendência, no entanto, era a decadência e o periódico deixou de circular cinco anos depois, em $1974 .{ }^{45}$

Já o Última Hora ficou em situação também difícil com o AI-5. Após resistência de Wainer em vendê-lo, nova proposta dos empreiteiros levou o dono do diário a cedê-lo em 1972 para Maurício Alencar e seus colegas por US\$ 1,5 milhão, divididos em 36 parcelas mensais. Antes disso, Wainer havia vendido o Última Hora paulista para a Folha de S. Paulo, de Otávio Frias, que lhe afirmou que a Federação das Indústrias do Estado de São Paulo - Fiesp ficara muito feliz com a operação. ${ }^{46}$

O controle dos dois jornais cariocas pelos empreiteiros consolidava o poder desses empresários, fornecendo-lhes instrumento para influir sobre outros segmentos sociais e atuar junto a cargos e posições no aparelho estatal. Os dois periódicos ganharam foco novo em sua orientação editorial, tornando-se porta-vozes das firmas de construção pesada. Seus anseios, projetos e ideias estavam presentes nas páginas dos jornais. Exemplo disso ocorreu em 26 de junho de 1972, quando o editorial do Correio da Manhã defendeu a prorrogação do mandato presidencial de Médici por um ano, com a justificativa de que seu fim deveria coincidir com o período dos governos estaduais. Segundo documentos de Geisel aos quais Elio Gaspari teve acesso, o então presidente da Petrobrás viu naquele gesto o dedo do ministro Andreazza. ${ }^{47}$

O Correio da Manhã circulou com tiragem decrescente até 1974 e o Última Hora foi editado ainda por mais um tempo. A Metropolitana, dos irmãos Alencar, foi à falência no final de 1974, após sofrer com atrasos de pagamentos de órgãos governamentais e ter os canais de financiamento para suas dívidas vetados pelos bancos. A revista $O$ Empreiteiro explica o fechamento da construtora carioca pelos atrasos governamentais e má gestão, citando o arrendamento do Correio da Manhã ${ }^{48}$ No entanto, os indícios apontam que o motivo que levou a empreiteira à falência tem relação com a transição po-

\footnotetext{
${ }^{45}$ FERREIRA, Marieta de Moraes $\mathcal{E}$ MESQUITA, Claudia. Os anos JK..., op. cit., p. 329-368.

${ }^{46}$ WAINER, Samuel. Minha razão de viver, op. cit., p. 280-1.

${ }^{47}$ GASPARI, Elio. A ditadura derrotada, op. cit., p. 206.

${ }^{48}$ Revista $O$ Empreiteiro, no 84 , janeiro de 1975.
} 
lítica entre as gestões Médici e Geisel e os conflitos políticos assumidos por Maurício Alencar nessa passagem entre os dois governos.

Não pretendíamos neste artigo ter realizado um balanço completo da trajetória dos veículos de comunicação no Brasil antes e depois da ditadura, mas apontar os interesses e influência dos empreiteiros nos veículos de imprensa no período. A forma de atuação das empresas do setor passou de ações pontuais e pagamentos para serviços específicos antes do regime para o controle de empresas de comunicação após o golpe. O reposicionamento político dos empresários da construção após 1964 permitiu que eles estabelecessem formas mais poderosas de influência política. Mais do que isso, a ação articulada de construtoras para controlar dois jornais de ampla circulação nacional demonstra nova escala do nível de organização e ação política desses empresários, mostrando que a coesão entre eles se fortalecia, tanto no âmbito das relações entre si como na comunhão de ideias que os uniam. Assim, esses jornais expressavam a visão comum que esses empreiteiros tinham sobre temas e aspectos da vida nacional. Os empreiteiros, já organizados em um partido próprio desde 1959, o Sinicon, agora tinham um canal para exposição de seus valores, concepções de mundo, projetos e demandas. O sindicato parece ter sido espaço para articulação e decisão para a ação dos empreiteiros na imprensa, encontrando-se ali os empresários que tomaram o Correio da Manhã e o Última Hora. O partido dos empreiteiros se tornava ainda mais complexo e poderoso, já que contava agora com dois diários nacionais e dispunha também de um especial representante direto no aparelho de Estado, o ministro Mário Andreazza. Este, após exercer por sete anos o cargo de ministro dos Transportes, durante as gestões Costa e Silva e Médici, voltou ao governo no período Figueiredo, como titular da pasta do Interior. Em 1984, Andreazza foi pré-candidato à presidência da República pelo PDS, sendo derrotado nas prévias do partido pela chapa encabeçada por Paulo Maluf. Alguns aliados seus e outros descontentes com a candidatura de Maluf formaram a Frente Liberal, que apoiava a chapa de Tancredo Neves e que depois fundou o PFL, atual Democratas (DEM). Apesar da origem vinculada ao principal líder dos empreiteiros durante o regime, a ideologia conservadora e a presença de remanescentes da ditadura em seu seio, o DEM não constitui hoje a única sigla política de atuação do partido dos empreiteiros. Pelo contrário, as doações de campanha legais e ilegais e as revelações recentes sobre propinas indicam como a atuação do partido dos empreiteiros se dá junto a variadas siglas políticas. E também continua bem forte junto à imprensa até os dias atuais. 


\section{Referências bibliográficas}

\section{Fontes primárias}

CLUBE DE ENGENHARIA. Luta pela engenharia brasileira. Rio de Janeiro: Clube de Engenharia, 1967.

Correio da Manhã.

GABEIRA, Fernando. O queé isso, companheiro? 26ª edição. Rio de Janeiro: Codecri, 1981. Informe Sinicon. Informe do Sindicato Nacional da Construção Pesada (Sinicon).

INSTITUTO DE ENGENHARIA. Engenharia no Brasil: 90 anos do Instituto de Engenharia, 1916-2006. São Paulo: Instituto de Engenharia, 2007.

QUINTELLA, Wilson. Memórias do Brasil grande: a história das maiores obras do país e dos homens que as fizeram. São Paulo: Saraiva / Vigília, 2008.

Revista $O$ Empreiteiro.

ROTSTEIN, Jaime. Em defesa da engenharia brasileira. Rio de Janeiro: Clube de Engenharia, 1966.

WAINER, Samuel. Minha razão de viver: memórias de um repórter. $10^{\mathrm{a}}$ edição. Rio de Janeiro: Record, 1988 [1987].

\section{Fontes secundárias}

ABREU, Alzira Alves de. A imprensa e a queda do governo de João Goulart. In: BRAGANÇA, Aníbal \& MOREIRA, Sonia Virgínia (org.). Comunicação, acontecimento e memória. São Paulo: Intercom, 2005, p. 13-21.

ANDRADE, Jefferson Ribeiro de. Um jornal assassino: a última batalha do Correio da Manhã. Rio de Janeiro: José Olympio, 1991.

AQUINO, Maria Aparecida de. Censura, imprensa, Estado autoritário: 1968-1978. Bauru: Edusc, 1999.

AREAS, João Braga. As batalhas de O Globo: ditadura militar, Lula x Collor, privatizações e a vitória do PT em 2002. Curitiba: Prismas, 2015.

Os Marinho: o monopólio brasileiro do setor de comunicação. In: CAMPOS, Pedro Henrique Pedreira E BRANDÃO, Rafael Vaz da Motta (org.). Os donos do capital: a trajetória das principais famílias empresariais do capitalismo brasileiro. Rio de Janeiro: Autografia, 2017, p. 196-226.

BANDEIRA, Luiz Alberto Moniz. Cartéis e desnacionalização: a experiência brasileira, 19641974. Rio de Janeiro: Civilização Brasileira, 1975.

CAMPOS, Pedro Henrique Pedreira. Estranhas catedrais: as empreiteiras brasileiras e a ditadura civil-militar, 1964-1988. Niterói: Eduf, 2014.

Um projeto de hegemonia em plena ditadura: o Clube de Engenharia e a campanha em defesa da engenharia brasileira (1964-1967). In: CORREA, Maria Letícia \& PAULA, Dilma Andrade de (org.). Intelectuais e desenvolvimento: perspectivas da pesquisa em história. Rio de Janeiro: Contracapa, 2015, p. 203-231. 
CARVALHO, Luiz Maklouf. Cobras criadas: David Nasser e O Cruzeiro. $2^{\text {a }}$ edição. São Paulo: EdSenac-SP, 2001.

CEZAR JÚNIOR, Gervásio. Revista Visão e Abdib: entre abalos e diferenças, as críticas ao II PND e a sustentação do projeto burguês. In: SILVA, Carla Luciana $\mathcal{E}$ RAUTEMBERG, Édina (org.). História e imprensa: estudos de hegemonia. Porto Alegre: FCM, 2014, p. 243-286.

FERRAZ FILHO, Galeno Tinoco. A transnacionalização da grande engenharia brasileira. Dissertação de mestrado em Economia, Unicamp, Campinas, 1981.

FERREIRA, Marieta de Moraes $\mathcal{E}$ MESQUITA, Claudia. Os anos JK no acervo da Biblioteca Nacional. In: BIBLIOTECA NACIONAL. Brasiliana da Biblioteca Nacional: guia de fontes sobre o Brasil. Rio de Janeiro: Fundação Biblioteca Nacional / Nova Fronteira, 2001, p. 329-368.

FICO, Carlos. O grande irmão: da Operação Brother Sam aos anos de chumbo; o governo dos Estados Unidos e a ditadura militar brasileira. $2^{\text {a }}$ edição. Rio de Janeiro: Civilização Brasileira, 2008 [2008].

GASPARI, Elio. A ditadura derrotada. São Paulo: Companhia das Letras, 2003. . A ditadura escancarada. São Paulo: Companhia das Letras, 2002.

MELO, Jorge José. Boilesen, um empresário da ditadura: a questão do apoio do empresariado paulista à Oban/Operação Bandeirantes, 1969-1971. Dissertação de mestrado em História, UFF, Niterói, 2012.

RAUTENBERG, Édina. A revista Veja e as empresas de construção civil durante a ditadura civil-militar. In: SILVA, Carla Luciana $\mathcal{E}$ RAUTEMBERG, Édina (org.). História e imprensa: estudos de hegemonia. Porto Alegre: FCM, 2014, p. 165-206.

ROUCHOU, Joëlle. Samuel: duas vozes de Wainer. $3^{\text {a }}$ edição. Rio de Janeiro: Ed. UniverCidade, 2004.

STEPAN, Alfred. Os militares na política: as mudanças de padrões na vida brasileira. Rio de Janeiro: Artenova, 1975 [1971].

Recebido: 17/03/2017 - Aprovado: 12/12/2017 